\title{
3 Pesearchs Surure \\ Climate Change and Hydropower Development in the Eastern Himalaya: Emerging Conflicts in the Upper Tista Catchment of Sikkim, India
}

Navin Rai ( $\sim$ navinrai101@gmail.com )

Sikkim Central University

Vimal Khawas

Sikkim Central University

\section{Short Report}

Keywords: Climate Change, Hydropower Development, Upper Tista Basin, People's perception, Environmental insecurity

Posted Date: April 9th, 2021

DOI: https://doi.org/10.21203/rs.3.rs-393218/v1

License: (c) (i) This work is licensed under a Creative Commons Attribution 4.0 International License. Read Full License 


\section{Abstract}

This paper assess the controversies and tensions being created by the target of ambitious hydropower development plans in the name of climate mitigating energy in the Upper Tista River Basin of Sikkim (India) which is a part of Eastern Himalayan region. However, in the face of climate change, hydropower projects have become a contested developmental paradigm in the Easter Himalayan region of Sikkim. The paper highlights potential issues and conflicts between climate mitigation approaches through hydropower projects and anti hydropower forces of local people. The paper critically examines pre and post hydropower development conflicts and cooperation along Upper Tista river basin. In fact, the region has witnessed that the Hydro Power Project have been undermining environmental and social security over the past years. The study also analyse the different roles of dam affected people, local politicians, NGOs and dam developers in advocating and protesting of the hydropower dam projects in the region.

Using an environmental security framework the study critically analyse the environmental risks and impacts being aggravated by combined forces of climate change and hydropower development in upper Tista catchment of Sikkim Himalaya (India).

\section{Introduction}

The Eastern Himalayan region is a part of Hindu Kush Himalaya encompasses a broad spectrum of ecological zones in Eastern Nepal, North-eastern India, Bhutan, Tibetan region and Yunan of China and Northern Myanmar (Devkota and Zhang, 2010). The culturally and ecologically diverse Eastern Himalayan region, considered climatically vulnerable, is currently also the target of ambitious hydropower projects (Joshi et al. 2018). While north-eastern states of India falls under the Eastern Himalaya has been considered as a 'Power house' or 'Future power house' of the country (Das, 2013).

Water stored in the high mountain in the form of snow and glaciers regulates the water supply, support the livelihood of millions of people (Biemans et. al., 2019; Immerzeel et al., 2019; Pritchard, 2019; Mishra et al., 2020). The region is therefore sources of many perennial rivers which is transboundary in nature and are the lifeline of downstream provinces and countries. Tista is a perennial river system originates from north-eastern states of India i.e. Sikkim. The literature show that the major parts of the Eastern Himalayas are undergoing warming trends and climate change impacts are disproportionate and influence lives and livelihoods variedly (Devkota and Zhang, 2010; Vaidya, et al. 2014; Bhadwal et al, 2019). It has been estimated that the temperature across the mountainous Hindu Kush Himalayan region will increase by about $1-2^{\circ} \mathrm{C}$ by 2050 (Shrestha et al. 2015). Correspondingly, changes in temperature and precipitation will have serious and far-reaching consequences for climate-dependent sectors, such as agriculture, water resources and health (Shrestha et al, 2015)

The fourth Assessment Report (AR4) of the Intergovernmental Panel on Climate Change (IPCC) shows that the Earth's average surface temperature has risen by $0.76^{\circ} \mathrm{C}$ since 1850 . The Intergovernmental Panel on Climate Change (IPCC) was set up jointly by the World Meteorological Organization and the United Nations Environment Programme to provide an authoritative international statement of scientific understanding of climate change. Literally, 'climate change' denotes to long-term change in the statistical distribution of weather patterns e.g. temperature and precipitation over decades to millions years of time (Rahman, 2012). However, in order to combat growing climate change all the countries has committed to goals for the reduction of global green house gas 
emissions through various international and national policies (Kyoto Protocol, 1987; Moser and Dilling, 2012; OECD, 2014).

Since the late 1800's, scientists have noted that climate change may be progressing at an alarming or accelerated rate, and it has believed that human beings may be contributing to this accelerated rate of climate change (Rehman, 2012; Bhandari, 2018; UNDP, 2019). Furthermore, UNDP (2019) highlights that GHG emissions are more than 50 percent higher than in 1990 level. Thus, immediate and drastic greenhouse gas emission reductions are needed to address climate change (Sovacool and Walter, 2018). Therefore, Clean Development Mechanism (CDM) under Kyoto Protocol and subsequent climate conferences gives preferences to renewable source of energy such as hydropower. Over the years, the development of hydropower therefore represents one of the options to mitigate climate change (Hudek, Zganec and Pusch, 2020).

Nonetheless, the concept of hydropower have been polarised by grouping of opinions into two extremes, i.e., prohydropower (proponents) and anti-hydropower (opponents) of it (Rai, 2020). The proponents portrays large hydropower as win-win and source of water supply, renewable electricity, climate mitigation, irrigation, and flood control and revenue generation to uplift poor people but contradictorily, a hydropower dam opponent considers it an epicentre of environmental and human insecurity through uncertainties of displacement, loss of arable land and Riverine ecology, inundation, and devastation in cultural heritage and livelihood (Huber 2019; Joshi, 2018; Rai, 2020). Furthermore, dominant pro-dam discourse celebrates hydropower as an uncomplicated, sustainable, and renewable source of energy indispensable to development objectives, such as green growth, climate change mitigation, and poverty alleviation (Huber, 2019). Over the years the public debate on climate change and large hydropower dams has entered a new phase. In the face of climate change hydropower dam construction comes with severe social, economic and ecological impacts (Zarfl et al. 2019). Upper Tista catchment of Sikkim Himalaya falls under the Eastern Himalayan region of India. The region is considered to be a geologically young folded mountain. In fact, rapidly expanding hydropower development in areas prone to geological and hydro-climatic hazards poses multiple environmental and technological risks (Huber, 2019). In fact, hydropower development in the Eastern Himalayan Region is characterized by inherent contentious and uncertainties, refuting the idea that dams constitute development projects whose impacts can be simply predicted, controlled and mitigated (Ahlers et al. 2015).

\section{Hydropower and Climate Change Nexus: Emerging Challenges}

The growing emissions of greenhouse gases are a central point of concern which leads to climate change (IPCC, 2007; UNDP, 2019). Despite many criticisms, the increasing greenhouse gases in the atmosphere of recent times leading to global warming are believed to be due to excessive use of fossil fuel based energy since industrial era (UNDP, 2019). In twenty first century, the climate change issue therefore has been discussed as a development issue (Vlassopoulos, 2012). A report of Joint Research Centre of the European Union (EU) has estimated that 75 percent of the global $\mathrm{CO}^{2}$ emissions result from the combustion of fossil fuels. Correspondingly, UNDP (2019) suggested that the high growth in fossil $\mathrm{CO}_{2}$ emissions was due to robust growth in energy use. This indicates that fossil fuel combustion is the largest single contribution to the greenhouse effect. Therefore, the cardinal nexus between climate change and hydropower development is a growing degree of Green House Gases (GHGs) emission from fossil fuel-based energy.

Increasing scientific evidence of human interference with the global climate system along with growing public concern about the environment pushed climate change onto the political agenda in the mid-1980s. Today, the 
major transformation of the global energy system is required for climate change mitigation, but in fact, energy demand patterns and supply systems are themselves subject to climate change impacts (Cronin et al. 2018). The components of energy system are also affected by climate change itself, via long-term changes in climate parameters, variability and extreme weather events (Field et al. 2013 as cited in Cronin et al. 2018). Mishra et al. (2020) examined the economic impacts of climate-led changes in river flow in two drainage basins, one each from the Karakoram and Central Himalaya region and found that hydropower plants with water storage facilities help reduce the impact of changes, but estimated impacts are higher for the higher capacity plants. In United States, hydropower generation has declined due to the impacts of precipitation variability and drought, enforcement of instream flow regulations, and a drop in capacity when dams are removed (EIA, 2015). Cherry et al. (2017) reviews hydro-climate changes in Far North and their impacts on hydropower, wherein the study on hydrologic impacts suggests that information resulting from climate change science has matured enough that it can and should be integrated into hydropower scoping, design, and management.

In the face of climate change, hydropower dams have emerged as the most renewable and sustainable source of energy that can contribute to mitigating the widespread potential human impacts of climate change, and it play a vital role in national strategies for delivering affordable and clean energy (IHA, 2019; Kyoto Protocol, 1987). The Clean Development Mechanism (CDM) under Kyoto Protocol therefore witnessed as one of the milestones in global efforts to protect the environment from excessive greenhouse gas emission and achieve sustainable development. Since 1987 Kyoto Protocol the idea of hydropower development have been re-strengthened by quoting it as a climate mitigating energy. Climate change awareness has increased the popularity of hydropower, now presented as renewable and clean energy that can replace fossil fuels as well as fulfil growing energy demands in Asia and elsewhere (Ahlers et al. 2015). Therefore, in $21^{\text {st }}$ century climate change is a key driver for hydropower. But in contrast, hydropower dams appeared the most controversial and are not necessarily the source of clean energy because they produce greenhouse emissions that can be substantial during the process of construction and subsequent land use change (Feranside, 2014; Fearnside, 2016; IPCC, 2011). Additionally, the literatures shows that greenhouse gas methane is produced from decomposition of submerged vegetation in newly submerged area behind dams. Yet, repackaging hydropower infrastructure as clean energy is confusing the resource with the instrument: water resource is renewable, yet dams are not (McCully, 1996). Correspondingly, as per the report of the World Commission on Dam (WCD) in 2000 explored that large dams' reservoirs could contribute between 1 and $28 \%$ of the global warming potential of GHG emissions. For instance, at recent past, the total annual methane emission has been assessed from major hydropower dams in Malaysia are estimated as 387.34 Gg CH yr. $^{-1}$ (Chow et al, 2018).

Furthermore, it has been estimated that nearly $90 \%$ of Indian Himalayan valleys would be affected by dam building and $27 \%$ of these dams would affect dense forest (SANDRP, 2012). The dam building activities are known to trigger adverse impacts on terrestrial and aquatic ecosystems and their biological diversity but the most conspicuous impacts are anticipated on the Riverine ecosystem and their functions (Pandit and Grumbine, 2012; Bhatt et al, 2017). On the other side, there is widespread consensus that climate change will impact water resources globally and regionally (Georgakakos, et al. 2014 as cited in Cherry, et al. 2017).

Nonetheless, healthy rivers are necessary for supporting life on earth. They help to maintain healthy ecosystem and balanced climate but most of the world's free flowing rivers have been sacrificed for the big hydropower projects. At recent past, Southeast Europe (SEE) has been witnessing a boom in hydropower plant (HPP) construction while as SEE includes global hotspots of aquatic biodiversity, it is expected that this boom will result 
in a more severe impact on biodiversity than that of other regions (Hudek, et al. 2020). Furthermore, Zarfl et al (2019) expressed that hydropower development will disproportionately impact areas of high freshwater megafauna richness in South America, South and East Asia, and the Balkan region. More recently in 2018, due to faulty construction, operation and the failure of authority to observe early warning signs, the under construction southern Laos's dam collapsed, killing at least 40 people, leaves hundreds missing and homes washed away (Ives, 2018; Huber, 2019). In fact, over the years, sustainability and win-win nature of hydropower dam project has been questioned by researchers, environmentalists, and social activists. Large dams, long viewed as a sustainable, renewable, and beneficial in climate mitigation, flood, and drought control and as essential to development, have become sites of major social and environmental conflicts (Rai, 2020). In a highly complex geological, ecological, cultural and political context, Eastern Himalayan region is widely regarded to be especially vulnerable to the effects of climate change, while hydropower as a development strategy makes for a toxic cocktail (Ahlers et al. 2015).

\section{Hydropower Development in the Face of Climate Change: People's Perception in Upper Tista Basin}

"Since last many years the weather patterns have been changing in the region, sometimes erratic rainfall and sometimes drought like condition. We are experiencing increasingly warmer condition nowadays. But additionally, during the last 10 years our village is in critical condition because of hydropower dam and its impacts on natural springs and agriculture"-

(64 years old man, farmer of Lower Samdong village near Tista Stage-V dam.)

The people's perception of weather patterns of Upper Tista Catchment are extracted with the help of 'weather chart' (Table 1) based on Participatory Rural Appraisal (PRA) and Focus Group Discussion (FGD) at Samdong-Kambal and Rakdong-Tintek GPUs near 510 MW Tista Stage-V dam. The various climatic indicators have been taken such as rainfall, hailstorm, warm and cold temperature, dry period and landslide in order to extract detail ground insights regarding the changing climatic conditions of a region. The changing climatic conditions of a region are drawn by comparing the people's perception of the past and the present experiences.

\section{Table 1. Climatic Hazards and Events}




\begin{tabular}{|c|c|c|c|c|c|c|c|c|c|c|c|c|c|}
\hline Indicators & Time & Jan & Feb & Mar & Apr & May & June & July & Aug & Sept & Oct & Nov & Dec \\
\hline & Past & ** & $\star * *$ & $\star \star \star$ & $\star \star *$ & $\star \star \star *$ & $\star \star *$ & $\star \star \star \star$ & $\star \star *$ & $\star \star \star$ & ** & * & * \\
\hline Rainfall & Present & * & * & * & ** & $\star \star$ & $\star \star \star$ & 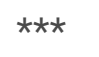 & $\star \star \star *$ & $\star \star$ & $\star \star$ & * & * \\
\hline Warm & Past & * & * & * & ** & ** & ** & ** & $\star \star$ & $\star \star$ & * & * & * \\
\hline Temp. & Present & * & * & $\star \star$ & $\star \star \star$ & $\star \star \star$ & $\star \star \star$ & $\star \star \star$ & $\star \star \star *$ & $\star \star \star$ & $\star \star$ & * & * \\
\hline Cold & Past & ** & $\star \star$ & $\star \star$ & $\star \star$ & * & * & * & * & * & $\star \star$ & $\star \star \star *$ & $\star \star \star \star$ \\
\hline Temp. & Present & 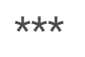 & $\star \star \star *$ & $\star \star$ & * & * & * & * & * & * & * & ** & $\star \star \star$ \\
\hline \multirow[t]{2}{*}{ Dry Period } & Past & * & * & * & * & * & * & * & * & * & $\star \star$ & $\star \star$ & ** \\
\hline & Present & $\star \star \star *$ & $\star \star \star *$ & $\star \star$ & * & * & * & * & * & * & ** & $\star \star \star *$ & $\star \star \star$ \\
\hline Hail & Past & & & * & $\star \star$ & * & & & & & & & \\
\hline Storm & Present & & & * & $\star \star$ & * & & & & & & & \\
\hline \multirow[t]{2}{*}{ Landslides } & Past & & & & & & * & $\star \star$ & $\star \star$ & ** & * & & \\
\hline & Present & & & & & & $\star \star$ & $\star \star \star *$ & $\star \star \star *$ & $\star \star$ & * & & \\
\hline
\end{tabular}

Based on Weather Chart

*Low, **Medium, ***High

The overall rainfall has reduced drastically in comparison to the past years. As per the people's perception, the overall temperature (hotness) has increased round the year since last 10-15 years. The agricultural productivity has also decreased as compared to earlier years due to increase in temperature. The villagers report that the region is a source of large amount of organic vegetables, large cardamom, pulses and cereal crops. The increasing trends of dryness due to increase in temperature, the production of vegetables has gone down. In fact, livelihoods of the local people are agrarian, where around $80 \%$ of the villagers' dependent upon agriculture and allied activities. Many people of the villages have left water intensive cultivation such as paddy because of water scarcity during the summer months. The high levels of impacts from climate change was recorded for paddy, maize, wheat, oil seeds, cardamom, ginger, spring water and fodder trees (Sharma and Rai, 2012). The region experiences extreme water scarcity during the months of November-March. As per the local residents, the onset of monsoon is observed to be delayed since last 11-12 years. Over the years, the people have been witnessing fluctuation in rainfall pattern. They claimed that the natural spring is being further accentuated and degraded by the tunnelling process of Tista-V Hydroelectric Project.

Similarly, the intensity of rainfall remains high during June, July and August months. It has been reported that due to the high intensity rainfall in the monsoon time leads to landslides and soil erosion. Additionally, it is said that aggressive landslides in the region is further aggravated by hydropower dams, tunnelling and road constructions. As far as the cold temperature is concerned, the severity (chilling weather) has gone up in the region in the month of December, January and February but rest of the months the warm temperature are more pronounced.

\section{People's Perception of Extreme Events and Changing Climate in Upper Tista Catchment}




\begin{tabular}{|c|c|c|}
\hline $\begin{array}{l}\text { Climatic } \\
\text { Parameter }\end{array}$ & Experienced Changes & Experienced impacts \\
\hline \multirow[t]{4}{*}{ Temperature } & $\begin{array}{l}\text {-Increased overall temperature } \\
\text { (Increased warmer days). }\end{array}$ & $\begin{array}{l}\text {-Insects and pests (diseases) are appearing in } \\
\text { crops. }\end{array}$ \\
\hline & -Intensity of hot days increased. & $\begin{array}{l}\text {-Erratic landslide in rainy season and drought } \\
\text { like condition in winter season. }\end{array}$ \\
\hline & -Not so extreme cold at winter. & $\begin{array}{l}\text {-Natural springs are drying and water scarcity } \\
\text { due to less rainfall. }\end{array}$ \\
\hline & & -Decreased in agricultural production. \\
\hline \multirow[t]{4}{*}{ Precipitation } & -Uneven rainfall. & -Water scarcity \\
\hline & -Shortening rainfall season. & \multirow{3}{*}{$\begin{array}{l}\text {-Drying up of natural springs from the original } \\
\text { aquifers. } \\
\text {-Reduced agricultural production. }\end{array}$} \\
\hline & -Less rainfall during winter. & \\
\hline & $\begin{array}{l}\text {-Rainfall intensity during summer } \\
\text { increased. }\end{array}$ & \\
\hline \multirow[t]{2}{*}{ Coldness/Hotness } & $\begin{array}{l}\text {-Duration of overall coldness } \\
\text { decreased. }\end{array}$ & \multirow[t]{2}{*}{$\begin{array}{l}\text {-Production in fruits and vegetables decreased } \\
\text { (Orange, cardamom and green vegetables). }\end{array}$} \\
\hline & -Increased overall hotness & \\
\hline Landslides & $\begin{array}{l}\text {-Facing aggressive landslides due to } \\
\text { erratic rainfall in monsoon months. }\end{array}$ & -blockage of road and village footpaths. \\
\hline \multirow[t]{2}{*}{ Water scarcity } & $\begin{array}{l}\text {-Almost } 80 \% \text { of natural springs dried } \\
\text { up and became seasonal. }\end{array}$ & $\begin{array}{l}\text {-Declined food productivity (Production level of } \\
\text { rice, orange and Large Cardamom reduced). }\end{array}$ \\
\hline & & -Food shortages. \\
\hline Drought & -longer dry period & -increased dry land \\
\hline
\end{tabular}

\section{Source. Based on Focus Group Discussion}

\section{People's Perception around Hydropower Development}

In the face of changing climatic condition, generally the hydropower project has explicitly accentuating the region and the environment. The mindset of the people has been critical towards the impact being aggravated by hydropower projects in Sikkim Himalaya during the last two decades. The people's perceptions particularly on hydropower in upper Tista catchment brings out the grounded insights of public repulsion to the hydropower projects. Wherein, the people conceptualised the dam as a "deteriorating agent of the environment and culture of a place".

"Yes we want development but it should be holistic, sustainable and inclusive. The development must be cultural and environmental friendly. The hydropower dams are terrible for our place since we have been experiencing its adverse negative impacts in our livelihoods and environment over the past years"-A member of an NGO. 
The drying up of natural spring is an important associated consequence of tunnelling and blasting in the region. In fact, agricultural production has gone down due to inappropriate climatic condition which is further been accentuated by the tunnelling and road construction. Agriculture is the major source of income in region. Consequently, the agricultural based livelihood in the River Tista basin faces two alarming environmental challenges in the form of hydropower development and changing climatic condition. There are two contradictorily conflicting perspectives in Upper Tista Basin in the context of hydropower projects i.e. The developmentalists perspectives who prefer hydropower development as a "bridge to attain socio-economic enhancement" whereas the environmentalists perspectives who critically voicing against the cascading hydropower dams in the region. The environmentalists and affected people of the region believed that environment, society and livelihood has been deteriorated alarmingly due to unsustainable way of water resource development. There is contestation that none of the power projects that are constructed in the mountain areas in the north east India including Sikkim are based on the geo-hydrological assessment (Sharma et al, 2015).

Participatory approach from different social groups (villagers, environmentalist, NGOs, social activists), political leaders, and policy makers become vital in this context to achieve secure and sustainable development. But the project affected place witnessed lacking village level participation despite growing emphasis on public participation or real participation by the affected people. Furthermore the Environmental Impact Assessment (EIA) reports are not prepared strictly based on scientific methodologies using latest tools and techniques (Sharma, Sharma and Dahal 2014). People's perceptions of hydropower dams and their impacts upon the villages and adjoining areas at different stages of Tista Stage-V project development are briefly summarised below.

Pre-construction Period: Hydropower project in the locale is being promoted by the government as a clean and sustainable energy and inclusive development imperatives such as revenue generators or economic growth and free energy suppliers. In fact, hydropower is advocated initially as a means of mass employment generation and poverty eradication of society. The pre-construction perception of hydropower dam in the locality was prodevelopment centric and pro-environment protection. When the idea of dam construction was first incepted during 1999-2000, the villagers had very little knowledge about the pros and cons of a Hydro power project. The stakeholders had painted a beautiful story of a happy ending wherein each members of a household would secure a regular job and the medical issues will be fulfilled with the establishment of a hospital in their own village. Correspondingly, the slogan of $100 \%$ job creation and provision of free electricity attracted educated unemployed and underemployed youths. Politicians and hydropower developers influenced the local people through citing hydropower project as holistic community and village developers.

It has witnessed that no or very less public level participation in the decision making process in pre-construction period wherein the project affected were not well informed and called for the public hearing. There seemed in fact polarized bi-party decision making process between higher authorities' i.e. state government and the project developers (NHPC) rather than including public and the stakeholder participation.

The natural environmental setting of river and locale area was perfect and not interfered by any water resource development. The villagers had surplus water availability as a natural perennial spring emanating from the aquifers. The water intensive crops such as paddy and large cardamom were most prominent crops they produced. Villagers did not have any ideas about the cracks which would appear in the lands and houses because of hazardous tunneling. In fact, the villagers were not informed about the $17 \mathrm{~km}$ long stretch of underground tunnelling from dam site to power house site. Later on the consequences of this tunnelling during construction and post-construction period brought cracks in the houses and land forms. The road construction and blasting 
transform the morphology of land due to land vibration which resulted into the uncertain landslides, rock falls and debris falls.

During Construction Period: At the initial stage of construction, the stakeholders of dam construction site tried to barricade the road to neutralize the interference of unknown people in their locality but in front of authority their effort became futile. They staged strong opposition collectively to resist the dam but result was not effective in front of police. Police as an active member of the authority came to the place and evacuated the people through harsh methods.

Administrative pressures to land donors were immense during construction period. Many times, villagers approached the District Collector (DC) to avoid the unnatural destruction through dam construction. The Member of Legislative Assembly (MLA), Panchayats and District Collector (DC) convinced local people for the consent by showing innumerable socio-economic facilities and opportunities from the company. Despite severe criticism, the constructional phase of the project started in the year 2000 and was commissioned in 2008. During construction period, people were explicitly voicing against the dam project. It was considered to be the most destructive phases of the project. Around 55 households (families) were displaced and resettled in a colony in the year 2007 by the project but the recent past condition of the resettlement and rehabilitation colony seemed dreadful condition due to arousing infrastructural problems. Respondents countered-510 MW Tista Stage-V projects which was designed and promoted in 2000s, which in fact sidelines local development and sustainability concerns for the sake of rapid capital accumulation and economic growth. The promises that had been made during the time of public hearing were totally overlooked by the developer and the government.

Villager perceives the tunnel beneath their village as very much fragile and as being constructed haphazardly. Project-affected people were worried about the acute water problem and changing behaviour of the environment that aggravated by hydropower dam in the region. Therefore, villagers have approached the District Collector (DC) to stop the environmentally unsustainable and unnatural destruction of dam construction. The real victims whose houses and lands were being taken away by the company were politically inactive. It was discussed during FGDs that the positive image of HEP was first imposed and introduced by the government by force in the region despite the public's resistance to the dam. The positive image of big hydropower project as a sustainable form of development for the people and the region were inculcated by the politician in order to maintain social harmony between different social groups and politicians. Therefore, under such circumstances villagers perceived hydropower dam as a sustainable form of water resources development despite being many public condemnation against the dams.

Many people were employed as a daily wage causal worker or labour during construction phase but removed almost all of them after construction being completed in 2008. In fact, the local people employed on contractual basis in clerical posts and as what the villagers quote it as casual labour or third grade job. Therefore, the policies of $100 \%$ regular employment facility to the villagers in the projected area were misinterpreted. The project-affected people countered the NHPC[1] (developer) and the government for not being allocated satisfactory compensation. The resettlement and Rehabilitation (R\&R) plan which envisages incentives for the displaced families but is yet to be fully implemented and monitored (Sharma and Pandey 2013).

Project-affected people were worried about the acute water problem and changing behaviour of the environment that aggravated by hydropower dam in the region. At the initial stage of tunnelling and damming of the river, the peripheral areas started getting impacted. Most of the respondents emphasized on the declining trend of 
agricultural production not merely from changing climatic condition but by tunnelling as well. In fact, tunnelling significantly reduced or made drying up of perennial spring of locality. The villagers' reports, due to fragile landscape, the region feared of landslides during rainy season (monsoon season) but the fragility of the landscape is further being accentuated by the hydropower dam and the underground tunnelling. The people of the region have been experiencing extreme landslides during monsoon period. Sharma, et al. (2014) further found in their research that the use of dynamites in road construction, underground tunnelling and cementation work has a terrible impact on springs which alters their occurrence and reduces their discharge. During conversations (FGDs) with affected-citizen of Rakdong village:-"We have been experiencing drying up of our natural spring at the fast rate since the construction of dam and tunnelling started. Most of the perennial spring became seasonal and most of them have dried up. Nowadays we are experiencing uncertain landslides in the places where we had not expected to be occurred"-64 years old man. Similarly, the people of the region were worried due to constructional activities which accentuated the region through 'unnatural land vibration'. They faced unnatural uncertainties due to these vibrations which aggravated socio-economic vulnerabilities through appearance of house cracks and water scarcity due to tunnelling.

Post Constructional Period: The Tista Stage-V project was commissioned in 2008. Subsequently, the project affected areas have been facing extreme forms of hydropower induced environmental impacts. Environmental insecurities are the major concerns. The villagers argued that the region is in environmentally vulnerable condition because of its fractured landform created by the dam building process during constructional phase (2000-2008). People and environment of the project-affected area are extremely impacted by tunnelling and damming. Consequently, almost $80 \%$ of the natural springs dried up, and facing acute water problem for household, livestock and agricultural purposes during winter season. Water insufficiency is the major problem in the villages. To tackle water scarcity, government of Sikkim (irrigation department) has facilitated metalled piped for water but villagers have critical views that merely water pipe does not have any meaning until there is water in the spring. Government has built many water tanks within the village but it remained dry throughout the year. They report hydropower development accelerated the water in the spring to dry. Till now government has not yet facilitated the water to individual stakeholder from perennial and sustained sources.

Extensive landslides have become a common disaster in the region during rainy season. Some of the houses are tilted and fractured because of unstable land due to underground tunnel. Project-affected people have been compensated with certain amount during pre-constructional period but the damages are still experienced after the dam has been commissioned. In this context the villagers have common complaints that- 'who will compensate us if in case of our houses and land property gets damaged now'. Water availability in the dry season has become a serious problem in the region which led to food insecurity. A 30 years old lady responded during FGD as- "The vegetables are not grown efficiently as before, because of water shortages and further aggravated by pests, now most of us are depending upon the vegetables coming from Siliguri, state of West Bengal". In fact, the region is exclusively depended on rainfall and natural springs for agriculture and livestock. The long stretch of tunnelling just below the villages led to the drying up of natural spring and has badly impacted the productivity of traditional food crops, fruits and vegetables.

The region is renowned in cardamom cultivation has turned into scarce or reduced cardamom cultivated land due to water scarcity. Cardamom is water intensive crops and has severely been affected by tunnelling and water shortages, which negatively impacting the economy of the region (Lepcha 2013). Paddy is cultivated in rainy summer season has comparatively good production in the region but over the years climatic uncertainty or untimely rainfall has affected the production level. The village development programmes as promised during 
public hearing such as free electricity, water facility and house repair to project-affected people during preconstruction and construction period are yet to be fulfilled. As part of the local area development program, hydropower companies had to undertake community development projects such as road, school repair and footpath construction, electrification and water supply for villages, and livelihood skill development in project affected areas (Chandy, et al. 2012). These community development programmes are also yet to be fulfilled.

[1] National Hydroelectric Power Corporation (NHPC) is an Indian Hydropower generation company that was incorporated in the year 1975 with an objective to plan, promote and organise an integrated and efficient development of hydroelectric power in all aspects. Later on NHPC expanded its objects to include other sources of energy like Solar, Geothermal, Tidal, Wind etc.

\section{Materials And Methods}

Study area: Whole Tista River basin drains a total geographical area of about 12,159 $\mathrm{km}^{2}$, draining Upper Tista basin in Sikkim Himalaya $\left(6930 \mathrm{~km}^{2}\right)$, middle Tista basin in West Bengal $\left(3225 \mathrm{~km}^{2}\right)$ and lower Tista basin in Bangladesh $\left(2004 \mathrm{~km}^{2}\right)$ before joining the great Brahmaputra in Bangladesh. This study is based on in-depth field survey in Upper Tista basin of Sikkim Himalaya. The total catchment area under Upper Tista River basin in Sikkim Himalaya is about $6930 \mathrm{~km}^{2}$. The study area covered a hydropower dam site i.e. $510 \mathrm{MW}$ Tista stage-V in east district of the Upper Tista River basin. In the basin, Government of India (GOI) has embarked on a fast-track dam building program.

Tista is a lifeline of Sikkim Himalaya. It is a perennial glacier-fed river which originates as Chhombo Chu from Khangchung Chho Lake at an elevation of $5280 \mathrm{~m}$ in North Sikkim. Among many, Rangit is the largest right bank tributary of Tista, which originates as Rangit Chu from Talung glacier at an elevation of $4080 \mathrm{~m}$ in west district of Sikkim. The Tista River and its tributary have been subjected to the cascades of hydropower projects over the last three decades. The study selected a hydropower sites in the basin. $510 \mathrm{MW}$ Tista-V hydropower projects is a run of the river scheme located near Dikchu of east Sikkim. The project comprises of $88.6 \mathrm{~m}$ high Concrete Gravity Dam with three penstocks of length $321 \mathrm{~m}$ and $17.2 \mathrm{~km}$ long Head Race Tunnel housed on left bank. The underground Power House near Sirwani with installed capacity of $510 \mathrm{MW}$ houses 3 units of $170 \mathrm{MW}$ capacities each designed to operate under the net rated head of $197 \mathrm{~m}$. The construction started in 2000 and commissioned in 2008.

Tools, Techniques and Data Collection: The study applied various tools and techniques during field study. Participatory Rural Appraisal (PRA) techniques of qualitative method have been used to extract ground data. This method seeks to understand the context and gathering information personally from the field through case study. The different tools and techniques of PRA are resource map, weather chart, crop calendar and social mapping. Similarly, study extracted field data through interview data (FGDs, In-depth Interview and Key Informants Interview), and through observation. The targeted people in in-depth interview were the community's people (local people), local politician (Panchayats), local contractors, project workers, SHGs and NGOs. The study conducted key informants interview to subject's experts, local researchers, and social activists. Similarly, FGD were taken with the community members who have been impacted by both climate change and hydropower development in the Tista river basin.

\section{Discussion}

Page $11 / 16$ 


\section{Hydropower and Climate Change: Emerging Contestation in Upper Tista Catchment of Sikkim: Over the two}

decades, it has been witnessed that the national drive for energy security (electricity) along with climate mitigation initiative has promoted a rapid expansion of hydropower development into isolated parts of the Himalayan state of Sikkim. In India impressive hydropower plans were being launched in 2003 wherein over 168 large dams for hydropower development have been proposed in the Easter Himalayan Region of India (Dukpa et al. 2019; Huber, 2019; Joy et al. 2014). In fact, a significant numbers of these dams are planned in Tista river basin of Sikkim Himalaya (Alhers, et al. 2015). Therefore, Tista river basin in Eastern Himalaya is being subjected to cascades of hydropower development and if all dams are constructed as proposed, the Indian Himalaya in general and Sikkim Himalaya in particular would have one of the highest average dam densities in the world (SANDRP, 2012; Grumbine and Pandit, 2013; Bhatt et al. 2017). Bhatt et al (2017) further investigated that if commissioned the already planned 18 large hydroelectric projects along Tista river basin, 52-88\% of the free-flowing river stretches will be diverted and $7.6-24 \%$ of the Riverine ecosystems will be converted into semi lacustrine by affecting more than 100 fish species. In terms of hydropower, it has estimated that the North Eastern Region of India has the potential of about 58,971 MW i.e. almost 40 percent of the country's total hydro potential (NEEPCO, 2017). However, over the past years the major national and state drivers for hydropower development in Sikkim Himalaya is climate change.

Despite the fact, the hydropower projects appeared a most contested developmental pathway across the Sikkim Himalaya witnessing anti-dam movements. For instance, the indigenous Bhutia communities, Lachungpas and Lachenpas, successfully contested all proposed hydropower projects and have managed to sustain an anti-dam opposition in their home region i.e. Lachung and Lachen of North Sikkim, they strongly oppose the project on social-cultural and humanitarian grounds" (Dukpa et al. 2019; Arora, 2007). In fact, politically, large dams serve as powerful symbol of modernization and national prestige (McCully, 1996; McCully, 2001). Likewise, in Sikkim, initially hydropower projects were seen and advocated as a symbol of progress, prosperity, source of revenue and national prestige. But contrastingly, the government and developers attracted the people by quoting hydropower as renewable, climate mitigating or win-win energy when public became vocal against socio-cultural and environmental destruction of it during the last two decades.

In fact, climate change is a key driver for hydropower in India in general and Upper Tista basin of Sikkim in particular. It has witnessed that since the last century, an increase in average global temperature has observed, and it is expected to increase further in future (Stoker et al. 2013; Ranzani et al. 2018). The intensity and frequency of precipitation are also expected to change, despite the trend differing with the season and the region (Ranzani et al. 2018). In Sikkim Himalaya, the problem of dying springs is being increasingly felt across the region because of impacts caused by changing climatic condition manifested in the form of rising temperature, rise in rainfall intensity in summer, reduction in its temporal spread with a marked decline in winter rain (Tambe et al. 2012). Notwithstanding, the climate change issue in Sikkim Himalaya have become more pronounced over the past years. It has been witnessing that monthly, seasonal and annual analysis of data based on Gangtok meteorological station for the period of 1957 to 2005 indicates a trend towards warmer nights and cooler days, with increased rainfall except in winter (Seetharam, 2008). The temperature in Gangtok (capital of state) has been rising at the rate of $0.2-0.3^{\circ} \mathrm{C}$ per decade and the annual rainfall is increasing at the rate of nearly $50 \mathrm{~mm}$ per decade (SAPCC, 2011). It has estimated that the temperature in Gangtok has risen by 1 to $1.5^{\circ} \mathrm{C}$ since 1957 . As per the record of two decades i.e. 1991-2010, the number of rainy days as well as the annual rainfall has decreased at the rate of 0.72 days/year and $17.77 \mathrm{~mm} /$ year respectively (Rahman, et al. 2012). Moreover, the rising average annual mean temperature in Sikkim at a significant manner and rainfall has shown as decreasing annually (Rathore, et.al. 2013). The warming is more pronounced in winter even though considerable warming has been observed in other

Page 12/16 
seasons too. The more cooling of days has been observed in the months of November and December (Mahamuni and Kulkarni 2012). In Sikkim Himalaya, it has been projected that by 2030s, the average annual temperatures are likely to rise by 1.8 to $2.1^{\circ} \mathrm{C}$ with respect to 1970 s (SAPCC, 2012).

Therefore, the State Action Plan on Climate Change (SAPCC) has been formulated by the Department of Science and Technology (DST) and Climate Change under the state government in 2011 to help communities adapt to changing climate and its consequences. But, Joshi (2018) critically analysed the State Action Plan on Climate Change (SAPCC) of Sikkim. She highlighted that the focus of the report is not on how large dams might exacerbate climate change impacts; rather it is on how climate change impacts might threaten the viability and sustainability of hydropower projects (SAPCC, 2012). Therefore, the climate policy framing is an exclusionary process, and climate mitigating interventions that are engineered essentially to address neoliberal economic concerns rather than environmental challenges are often the source of multiple new conflicts (Joshi, 2018). In the face of climate change (SAPCC, 2012) hydropower as a developmental pathway in the climatically vulnerable Upper Tista catchment is predominant with controversies over the socio-cultural and environmental impacts being aggravated by power projects (Menon, 2003; Arora, 2007; 2009; Khawas, 2016).

\section{References}

Ahlers R, Budds J, Joshi D, Merme V. Framing Hydropower as Green Energy: Assessing Drivers, Risks and Tensions in the Eastern Himalayas. Earth System Dynamic. 2015;195-204. Doi:10.5194/esd-6-195-2015. www.earth-systdynam.net/6/195/2015. Accessed on 22/09/2020.

Arora V. Unheard Voices of Protest in Sikkim. Economic and Political Weekly, 2007;42:3451-3454.

Arora V. Gandhigiri in Sikkim. Economic and Political weekly. 2007; 27-28.

Arora V. There are All Set to Dam (n) Our Future: Contested Development through Hydel Power in Democratic Sikkim. Sociological Bulletin, Indian Sociological Society. 2007;94-114.

Bedsworth LW, Ellen H. Adaptation to Climate Change. Journal of American Planning Assiciation. 2010: 477-495.

Berga L. The role of hydropower in climate change mitigation and adaptation: a review. Engineering. 2016; 2:313-8. https://doi.org/10.1016/j. ENG.2016.03.044.

Bhadwal S, Sharma G, Ganesh G, Sen SM. Livelihoods, gender and climate change in the Eastern Himalayas. Environmental Development. 2019;68-77. http://doi.org/10.1016/j.envdev.2019.04.008 Accessed on 20/09/2020.

Bhatt JP, Tiwari S, Pandit MK. Environmental impact assessment of river valley projects in upper Teesta basin of Eastern Himalaya with special reference to fish conservation: a review. Impact Assessment and Project Appraisal. 2017;35:.340-350. DOI: 10.1080/14615517.2017.1354642. Accessed on 23/1/2018

Biemans H, Siderius C, Lutz AF, Nepal S, Ahmad B, Hassan T. Importance of snow and glaciers melt water for agriculture on the Indo-GANGETIC Plain. Nat. Sustain. 2019;594-601. Doi:10.1038/s41893-019-0305-3.

Chandy T, Rodney J, Keenan R, John P, Peter S. Impacts of Hydropower Development on Rural Livelihood Sustainability in Sikkim, India: Community Perceptions. Mountain Research and Development. 2012;117-125. 
Cherry JE, Knapp C. Trainor S, Ray A, Tedesche M, Walker S. Planning for climate change impacts on hydropower in the Far North. Hydrol. Earth Syst Sci. 2017;133-151. Doi: 10.5194/hess-21-133-2017.

Das PK. North-East, 'The Power House of India': Prospects and Problems. IOSR Journal of Humanities and Social Science (IOSR-JHSS). 2013;18:36-48. www.iosrjournals.org. Accessed on 23/09/2020.

Devkota LP, Zhang F. Climate Change in the Eastern Himalayas: Observed Trends and Model Projections. 2010.

Fearnside PM. Impacts of Brazil's Madeira River Dams: Unlearned lessons for hydroelectric development in Amazonia. Environ. Sci. Policy. 2014;38:164-172.

Gopalakrishnan M. Resettlement and rehabilitation lessons from India. In: Tortajada C, Altinbilek D, Biswas AK, editors. Impacts of large dams: A global assessment Series on Water Resources Development and Management. New York: Springer; 2012. pp. 357-378.

Grumbine E, Pandit MK. Threats from India's Himalaya Dams. Science, American Association for the advancement of Science. 2013;339:36-37.

Hudek HH, Pusch MT. A review of hydropower dams in Southeast Europe-distribution, trends and availability of monitoring data using the example of a multinational Danube catchment subarea. Renewable and Sustainable Energy Review. ScienceDirect. 2020;117. http://doi.org/10.1016/j.rser.2019.109434. Accessed: 20/09/2020.

Immerzel WW, Lutz AF, Andrade MA, Biemans H, Bolch T. Importance and vulnerability of the world's water tower. Nature. 2019;577:364-369. Doi:10:1038/s41586-019-1822-y.

IPCC (2011). IPCC Special Report on Renewable Energy Sources and Climate Change Mitigation, edited by: Edenhofer, O., Pichs-Madruga, R., and Sokona, Y., Cambridge University Press, Cambridge, UK and New York.

IPCC (2014) Mitigation of Climate Change. http://report.mitigation2014.org/drafts/final-draft-postplenary/ipccwg3ar5final-draft-postplenarychapter7.pdf. Accessed on 20/09/2020.

Ives M. A Day Before Laos Dam Failed, Builders Saw Trouble. The New York Times. 2018. http://www.nytimes.com/2018/07/26/world/asia/laos/laos-dam-collapse.html. accessed on 20/09/2020.

Johnson et al. Integrated Solutions for the Water-Energy-Land Nexus: Are Global Models Rising to the Challenge? Water. 2019. Doi:10.3390/w11112223. Accessed on 21/09/2020.

Joshi D, Platteeuw J, Singh J, Teoh J. Water down? Civil society organizations and hydropower development in the Darjeeling and Sikkim regions, Eastern Himalaya: A comparative study. Climate Policy, 2018;63-77. http://doi.org/10.1080/14693062.2018.1557035. Accessed on 10/2/2020.

Joy KJ. Mahanta C, Das PJ. Hydropower Development in Northeast India: Conflicts, Issues and Way Forward. 2013. Available online: http://tinyural.com/yc5fhf5u (accessed on 19/08/2017.

Khawas V. Hydro-Fever in the Upper Tista Basin and issues of Regional Environmental Security. Journal of Politics and Governance. 2016;49-56.

Khawas V. Dynamics of Hydropower Development and Regional Environmental Security in the Teesta Basin. Sikkim Express. 2015: 2. 
Lepcha T. Hydropower Projects on the Teesta River: movements against Mega dams in Sikkim. In: Das JD, Mahanta C, Joy KJ, Paranjape S, Vispute S, Editors. Water conflicts in Northeast India: A compendium of case studies. Forum for Policy Dialogue on Water Conflicts in India, Pune;2013.

Macchi M, Amanda MG, Brigitte H, Dhrupad C. Climate Variability and Change in the Himalayas: Community perceptions and responses. International Centre for Integrated Mountain Development. 2011. Kathmandu, Nepal.

Mahamuni K, Himanshu K. Groundwater resources and spring hydrology in south Sikkim, with special references to climate change. In: Arrawatia ML, Tambe S, editors. Climate Change in Sikkim: Patterns, Impacts and Initiatives. Gangtok: Information and Public Relations Department Government of Sikkim. 2012.

McCully P. Silenced Rivers. Zed Books Ltd., London. 1996.

McCully P. Tropical Hydropower is a Significant Source of Greenhouse Gas Emissions: A response to the International Hydropower Association. International Rivers Network;2004.

Menon M. Saved! The Story of Rathong Chu. The ecologist Asia. 2003:11

Mishra SK, Veselka TD, Prusevich AA, Grogan DS, Lammerrs R, Rounce DR, Ali SH, Christian MH. Differential Impact of Climate Change on the Hydropower Economics of Two River Basins in High Mountain Asia. Environmental Science. 2020. http://doi.org/10:10.3389/fenvs.2020.00026. Accessed on 21/09/2020.

Molden DJ, Vaidya RA, Shreshtha AB, Rasul G, Shrestha MS. Water infrastructure for the Hindu Kush Himalaya. International Journal of Water Resources Development. 2014;30:60-77. DOI:10.1080/07900627.2013.859044.

NEEPCO. (North Eastern Electric Power Corporation Limited): A Government of India Enterprise. 2017.

Pandit MK, Grumbine RE. Potential effects of ongoing and proposed hydropower development on Terrestrial Biological diversity in the Indian Himalaya. Conservation and Biology. 2012;26:1061-1071.

Pritchard HD. Asia's shrinking glaciers protect large populations from drought stress. Nature. 2019;569:649-654. Doi:10:1033/s41586-019-1240.

Rahman RR, Senapati PC, Ngachan SV, Kumar A. An Analysis of Past Three Decade Weather Phenomenon in the Middle-Hill of Sikkim and Strategies for Mitigating Possible Impact of Climate Change on Agriculture. Information and Public Relation, government of Sikkim. 2012.

Ranzani A, Bonato M, Patro ER, Gaudard L. Hydropower Future: Between Climate Change, Renewable Deployment, Carbon and Fuel Price. Water. 2018. Doi: 10.3390/w10091197. Accessed on 11/2/2020.

Rathore LS, Attri SD, Jaswal AK. State Level Climate Change Trends in India. Meteorological Monograph, India: Government of India. 2013.

SANDRP. Indian Himalayas moving towards highest Dam Densities in the World. South Asian Network on Dams, Rivers \& People. 2012.

Seetharaman K. Climate Change Synthetic Scenario over Gangtok. In: Arrawatia ML, Tambe S, editors. Climate Change in Sikkim Patterns, Impacts and Initiatives. Information and Public Relation Department, Government of Sikkim Gangtok. 2012.

Page 15/16 
Sharma G, Trilochan P. Water Resource Based Developments in Sikkim: Exploration of conflicts in the east and west districts. In: Das PJ, Mahanta C, Joy KJ, Paranjape S, Vispute S, editors. Water Conflicts in Northeast India: A compendium of case studies. Forum for policy dialogue on water conflicts in India; 2013.

Sharma G, Durga PS, Dahal DR. Water conflicts and benefits related to hydropower projects: A Case study from Sikkim. Abhilasha, Development Area, Gangtok Sikkim-737101, India.

Shrestha AB, Agrawal NK, Alfthan B, Bajracharya SR, Marechal J, Van OB. The Himalayan Climate and Water Atlas: Impact of Climate Change on Water Resources in Five of Asia's Major River Basins. ICIMOD, GRID-Arendal and CICERO; 2015.

Sovacool BK and Walter G. Internationalizing the political economy of hydroelectricity: Security, development and sustainability in hydropower states. Review of International Political Economy. 2018.

Stocker TF, Qin D. Plattner GK, Tignor M, Allen SK, Boschung J, Nauels A, Xia Y, Bex V, Midgley PM. Climate Change 2013: The Physical Science Basis. IPCC: Cambridge, UK; New York, NY, USA;2013.

Tambe S, Kharel G, Arrawatia ML. Kulkarni H, Mahamuni K, Ganeriwala AK. Reviving dying springs: climate change adaptation experiments from the Sikkim Himalaya. In: Arrawatia ML, Tambe S, editors. Climate Change in Sikkim: Patterns, Impacts and Initiatives. Information and Public Relations Department Government of Sikkim, Gangtok; 2012.

Vaidya RA, Sharma E. Research Insights on Climate and Water in the Hindu Kush Himalaya. International Centre for Integrated Mountain Development (ICIMOD), GPO Box 3226, Kathmandu, Nepal; 2014.

Vaidya RA, Sharma E. Research Insights on Climate and Water in the Hindu Kush Himalaya. International Centre for Integrated Mountain Development; 2014.

Vaidya RA. Governance and management of local water storage in the Hindu Kush Himalayas. International Journal of Water Resources Development. Routledge, 2015;31:253-268.

Vlassopoulos CA. Competing definition of climate change and the post-Kyoto negotiation. International Journal of Climate Change Strategies and Management. Emerald Group Publishing Limited. 2012;4:104-118.

http://doi.org/10.1108/175686912112. Accessed: 21/07/2020.

WCD. Dams and Development: A new framework for decision making. The report of the world commission on dams. London and Sterling, VA: Earthscane Publication Ltd, 2000.

Zarfl C, Berlekamp J, He F. Jahnig S, Darwall W, Tockner K. Future large hydropower dams impact global freshwater megafauna. Scientific Reports, natureresearch; 2019. https://doi.org/10.1038/s41598-019-54980-8.

Zhang X, Li H, Deng ZD, Ringler C, Gao Y. Impacts of climate change, policy and Water-Energy-Food nexus on hydropower development. Renewable Energy; 2017. Doi:10.1016/j.renene.2017.10.030. 